\title{
An Empirical Study on the Impact of Policy on Stock Volatility of Construction Materials
}

\author{
Yuanqiao Long 1,a* \\ ${ }^{1}$ School of Mathematics and Economics, Sichuan University, Sichuan 610065, China \\ a (longyuanqiao0923@163.com)
}

\begin{abstract}
In recent years, China's traditional manufacturing industry has been facing a situation of transformation, resulting in frequent fluctuations in its stock prices. As a representative of the traditional manufacturing industry, the stock prices of the Construction Materials industry are often linked with policies. Therefore, it is essential to explore how policies affect the Construction Materials stocks. In this paper, the Iterative Cumulative Sums of Squares (ICSS) method is used to examine the daily rate of return of the CNI Construction Materials index between January 2015 and July 2021 to find the structural breakpoints. Then compare the effects of different policies according to the characteristics of stock volatility based on the Garch model with dummy variables and connect it with related policies. Besides, the CNI coal index and Real Estate index are introduced into the ADL regression model to explore the influence of other industrial policies on the Construction Materials industry. The results show that, firstly, energy conservation and green supervision to eliminate enterprises with backward production capacity can effectively reduce Construction Materials stocks' volatility. Second, the persistence of stock price fluctuations in the Construction Materials industry is significantly related to the abrupt changes caused by policies. Third, boosting the real estate price can increase the stock price of Construction Materials but increase the volatility, while raising the coal price forces the Construction Materials industry to transform to clean energy, and energy-saving is conducive to the steady growth of the stock price.
\end{abstract}

Keywords: Green development policy; supply-side reform, structural change point; stock volatility; GARCH model with the dummy variable

\section{INTRODUCTION}

As the new development theory gradually are deeply rooted in people's minds, China is eliminating high energy consumption and high pollution enterprises. Thereby, reducing energy consumption, using clean energy, and developing new green Construction Materials has become the new direction of the Construction Materials industry transformation. Since the "carbon neutral, carbon peak" was included in the "14th FiveYear Plan", traditional manufacturing stocks such as Construction Materials industry stocks have suffered a specific impact, which stimulates us to examine the impact of policies on Construction Materials industry stocks.

Many scholars considered that the important events contribute to structural changes, such as macroeconomic events, reform policies and crisis events. Zhuo and Kumamoto(2020) measured the impact of COVID-19 and government containment policies on global stocks by using the panel VAR model ${ }^{[1]}$. Fang and Wang(2009) applied the ICSS model to find that the Chinese stock market volatility mutation led to its persistence ${ }^{[2]}$. Babikir(2012) believed that structural breakpoints should be considered, especially in the long-term prediction of stock market volatility ${ }^{[3]}$. Wen and Liu (2011) believed that macro factors and stock volatility of related industries had a significant impact on the processing and manufacturing industry ${ }^{[4]}$. $\mathrm{Li}$ and $\operatorname{Huo}(2010)$ used the ADL model to prove that energy consumption and structure have no long-term impact on economic growth $^{[5]}$.

The contribution of this paper is mainly reflected in the use of the latest data from 2015 to 2021 to supplement the domestic policy research on the stock price volatility of the Construction Materials industry. Then find out the main force is the policy of the green transformation to a build-up of the stock and the decisive power to reduce the volatility of the stock. Secondly, by studying the influence of different policies on the supply side and the 
demand side on stock volatility, it concludes that the green development of the supply-side can reduce the stock price risk of the Construction Materials industry and guide the steady development of the industry. In summary, the paper takes the significant representative manufacturing industry--the Construction Materials as an example, which promotes study in the economic significance of the green transformation of the manufacturing industry and provides the empirical methods as well.

\section{DATA COLLECTION AND VARIABLE SELECTION}

The data used in this study are from the "CNI Index", including daily data of the CNI Construction Materials Index from January 2015 to July 2021. The sample selects the top 30 Shanghai and Shenzhen A-shares stocks with an average daily total market capitalization in the recent six months as the CNI Construction Materials Index sample stocks. According to the CNI industry classification standard, the ICSS method is used to analyse the influence of the policy changes of the Construction Materials industry on the breakpoint of the Construction Materials index. Moreover, the price of Construction Materials is affected by various factors, including the law of supply and demand, technological progress in inflation, government macro-control policies, and regional development degree. Through the ISM method, Guo ${ }^{[6]}$ concluded that the investment policy of infrastructure Construction and monetary policy are the main factors affecting the price of Construction Materials, followed by the price of raw materials. Since Construction Materials consume much coal and are greatly influenced by coal prices, and the real estate index can measure real estate prices, we extract the CNI coal index and CNI real estate index of the state Securities Securities from January 2015 to July 2021 as explanatory variables, and the CNI Construction Materials index as explained variables.

\section{RESEARCH METHODOLOGY}

\subsection{ICSS based stock mutation point model}

The ICSS algorithm is applied to explore the influence of significant policies on stocks. According to the concepts and theorems of Brownian bridge motion, $\max _{k}\left|\sqrt{\frac{T}{2}} D_{k}\right|_{\text {it exceeds a predetermined confidence }}$ threshold, $\mathrm{K}^{*}$ is considered the estimated breakthrough point. Under the assumption of constant variance, when the random variable is identically distributed, the progressive distribution of $\mathrm{D}_{\mathrm{k}}$ is Brownian Bridge motion. The $D_{k}$ threshold at $99 \%$ significant level is 1.628 . The model is as follows:

$$
\begin{gathered}
\text { breakpoints }=\sup _{k}\left|\sqrt{\frac{T}{2}} D_{k}\right| \\
D_{k}=\frac{C_{k}}{C_{T}}-\frac{k}{T}, k=1,2,3, \ldots T \\
C_{k}=\sum_{i=1}^{k} \varepsilon_{t}^{2}
\end{gathered}
$$

where $C_{k}$ is the cumulative sum of squares of disturbed terms after stock price standardization.

\subsection{Garch model with dummy variables}

As a modern financial event sequence model, the Garch model is modelled based on the characteristic of fluctuation aggregation. Volatility aggregation theory explained that there is a specific relationship between current volatility and past volatility. Moreover, the concept of variance also extends to conditional variance correspondingly. The so-called conditional contrast refers to the variance of general information at past moments. Garch model considers that the conditional variance of the current period is a linear combination of the conditional variance of the past $\mathrm{N}$ periods and the square of the sequence. In contrast, the sequence results from the conditional variance of the current period and the white noise.

$$
\begin{gathered}
\varepsilon_{t}=\sigma_{t} \eta_{t}, \eta_{t} \sim N(0,1) \\
r_{t}=\ln \left(\frac{P_{t}}{P_{t-1}}\right) \sim N\left(\mu, \sigma_{t}^{2}\right) \\
\sigma_{t}^{2}=\omega+\alpha_{1} \varepsilon_{t-1}^{2}+\beta_{1} \sigma_{t-1}^{2}
\end{gathered}
$$

Where $r_{t}$ is the daily return rate of the CNI Construction Materials index, $\mu$ is the average daily return rate, and $\mathrm{P}_{t}$ is the daily closing price of Construction Materials. Based on the above formula, according to the GARCH model of dummy variables proposed by Fang and Wang(2009) ${ }^{[2]}$, we introduce the variance mutation points detected by ICSS as dummy variables. They are $D_{1} 、 D_{2} 、 D_{3} 、 D_{4} 、 D_{5}$ and $D_{6}$ respectively.

$$
\sigma_{t}^{2}=\omega+\alpha_{1} \varepsilon_{t-1}^{2}+\beta_{1} \sigma_{t-1}^{2}+\sum_{m=1}^{6} \gamma_{m} D_{m}
$$

\subsection{Autoregressive Distributed Lag Model and ECM Model}

Jorgenson proposed an autoregressive distributed lag model of order (P, Q), based on which exogenous variables and the lag order of exogenous variables were introduced. According to the influencing factors of price fluctuations of Construction Materials proposed by $\mathrm{Guo}^{[6]}$, it was believed that Construction Materials were 
mainly affected by the coal index and real estate index, so the model was constructed as follows:

$$
\ln P_{t}=c_{0}+c_{1} \ln P C_{t}+c_{2} \ln P E_{t}
$$

Then ECM model is obtained through the above regression, and the ECM model was introduced to compare the long-term and short-term models.

$$
\Delta \ln P_{t}=c_{0}+\sum_{i=1}^{p} c_{i} \Delta \ln P_{t-i}+\sum_{j=1}^{m} \gamma_{i} \Delta l n P C_{t-j}+\sum_{k=1}^{q} \varphi_{i} \ln P E_{t-k}+\lambda E C M_{t-1}
$$

where $\ln P_{t}$ represents the logarithmic index of the CNI Construction Materials index. $\ln P C_{t}$ represents the logarithmic index of the CNI coal index. $\ln P E_{t}$ represents the logarithmic CNI real estate stocks index.

\section{EMPIRICAL RESULTS AND ANALYSIS}

\subsection{The point of abrupt change in stock structure caused by the policy}

As can be seen from Figure 1, the structural fracture dates of the CNI Construction Materials index are Respectively June 15, 2015, March 14, 2016, December 29, 2017, June 11, 2019, and January 20, 2020

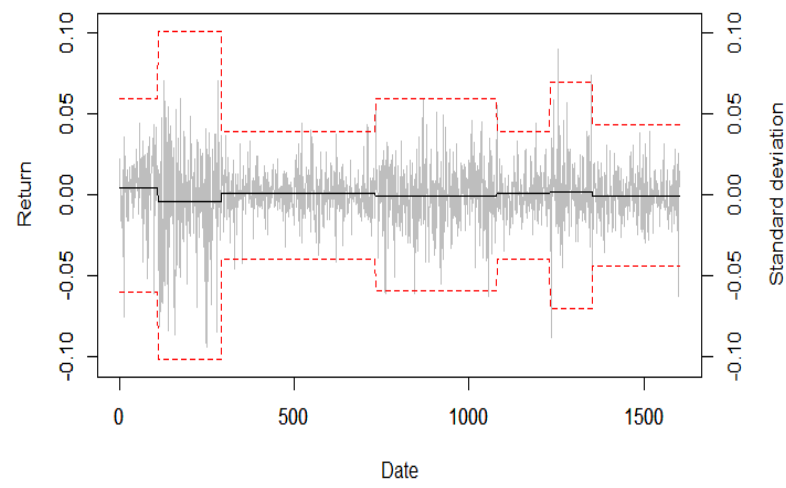

Figure $1 \mathrm{CNI}$ building materials index returns with standard deviations

Comparing Table 1 and the related policies, on June 15,2015 , the comprehensive utilization tax rebate policy is stricter than the previous policy, mainly reflected in three aspects: First, the comprehensive utilization of resources tax rebate is changed from $100 \%$ immediately to $70 \%$. Second, enterprises must meet the request of "Cement Industry air pollutant emission standards". Third, the $40 \%$ waste slag utilization rate makes lowgrade cement enterprises more difficult and even makes them withdraw from the preferential policy. Thus, the unit cost of Construction Materials enterprise production increases, the stock market risk increases, resulting in increased stock volatility. On March 14, 2016, "the Key Work Plan of Industrial Energy Conservation Supervision in 2016" was proposed. It included mandatory energy consumption quota standards and the request of energy conservation work, and eliminating energy-consuming enterprises. Therefore, the policy reduced the competition and cost of energy-saving enterprises and thus reduced stock price fluctuations. On October 25, 2017, the Department of Housing Construction issued "10 New Technologies for The Construction Industry (2017 Edition)", which aims at updating green constructions, construction disaster prevention and mitigation, Construction energy conservation and construction informatization based on BIM, big data, cloud computing, GIS, IOT. Thus the stock price of Construction Materials increased rapidly and fluctuated slightly. On June 11, 2019, the Department of Housing Construction released "a series of 28 evaluation standards for green Construction Materials", making the Construction Materials industry develop in a healthy and stable environment. On January 20, 2020, due to the impact of COVID-19, The State Council issued various policies and measures to prevent and control the epidemic, and the overall stock market fluctuated greatly. After July 2020, the Construction Materials industry also entered the resumption of work and production process and eliminated relatively backward enterprises during the epidemic period, making the overall level of the Construction Materials industry more balanced. At the same time, with the development of intelligent, digital and green environments, the volatility of Construction Materials stocks will gradually become stable.

Table 1 CNI building materials index

\begin{tabular}{lll}
\hline Time table & $\begin{array}{l}\text { Standard } \\
\text { deviation }\end{array}$ & Breakpoints \\
\hline Period $_{1}(1-108)$ & 0.0200 & $2015-06-15$ \\
Period $_{2}(109-289)$ & 0.0338 & $2016-03-14$ \\
$\operatorname{Period}_{3}(290-731)$ & 0.0131 & $2017-12-29$ \\
$\operatorname{Period}_{4}(732-1079)$ & 0.0198 & $2019-06-11$ \\
$\operatorname{Period}_{5}(1080-1231)$ & 0.0132 & $2020-01-20$ \\
$\operatorname{Period}_{6}(1232-1353)$ & 0.0233 & $2020-07-24$ \\
$\operatorname{Period}_{7}(1354-1602)$ & 0.0145 & $2021-07-30$ \\
\hline
\end{tabular}

\subsection{Research on stock characteristics by stages based on Garch Model}

As shown in Table 2, without introducing dummy variables, the sum of $\alpha$ and $\beta$ is very close to 1 , indicating that fluctuations are persistent. However, the sum of $\alpha$ and $\beta$ decreases rapidly when the volatility mutation dummy variable is introduced, indicating that market volatility's strong persistence disappears when the volatility mutation structure is taken into account. By adding the coefficients of dummy variables in sequence $\sum_{m=1}^{k} \gamma_{m}$

( $\mathrm{k}=1-6)$, the fluctuation of Period 3 and Period 5 decreases the most, indicating that energy-saving 
emissions and green development supervision to eliminate backward production capacity enterprises can promote the stable development of the Construction Materials industry.

Table 2 Changes of GARCH model parameters after the introduction of dummy variables at mutation points

\begin{tabular}{cccccccccc}
\hline Case & $\omega$ & $\alpha$ & $\beta$ & $\gamma_{1}$ & $\gamma_{2}$ & $\gamma_{3}$ & $\gamma_{4}$ & $\gamma_{5}$ & $\gamma_{6}$ \\
\hline A & $1.46 \mathrm{E}-04$ & 0.0629 & 0.592 & $2.25 \mathrm{E}-04$ & $-3.14 \mathrm{E}-04$ & $8.63 \mathrm{E}-05$ & $-8.55 \mathrm{E}-05$ & $1.3 \mathrm{E}-04$ & $-1.24 \mathrm{E}-04$ \\
$\mathrm{~B}$ & $5.4 \mathrm{E}-06$ & 0.0638 & 0.922 & & & & & & \\
\hline
\end{tabular}

\subsection{Research on stock related industry based on ADL model}

According to the regression results, there is a significant long-term co-integration relationship between the coal index, real estate index and Construction Materials index. When the coal index increases by $1 \%$, the Construction Materials index increases by $0.377 \%$. When the real estate index increases by $1 \%$, the Construction Materials index increases by $0.631 \%$. It shows that the policy affects the price of Construction Materials itself and affects its upstream industry (coal, etc.) and market demand (real estate, infrastructure construction). Properly stimulating the demand for real estate can enhance the stock price of Construction Materials, but at the same time, it will increase its volatility. The price of coal and the stock price of Construction Materials often have a negative impact. However, the positive impact here indicates that the rise of coal price may lead Construction Materials enterprises to slowly turn to clean energy, eliminate backward production capacity. enterprises, enhance consumer confidence, and further improve their overall stock price. Given the result of Table 3, Whether in the short or long term, the index of Construction Materials has a close relationship with other variables. It can affect the stock price of Construction Materials by influencing relevant industrial policies. The coefficient of the ECM indicates that the short-term impact on the index of Construction Materials will be corrected by $0.27 \%$ within a month.

Table 3 ECM results

\begin{tabular}{ccc}
\hline Variable & Coefficient & Prob \\
\hline$\Delta \ln P_{t-1}$ & -1.088321 & 0 \\
$\Delta \ln P C_{t}$ & 0.244474 & 0.0326 \\
$\Delta \ln P E_{t}$ & 0.679515 & 0 \\
$E C M_{t-1}$ & 0.002735 & 0.9161 \\
\hline
\end{tabular}

\section{Conclusion and Suggestions}

\subsection{Conclusion}

This paper mainly explores the impact of green development policies and real estate development policies on Construction Materials industry stocks. On the one hand, green development policy represents the policy of industrial transformation itself, which is the reform of the supply side. The real estate development policy represents the policy of the consumption industry closely related to related industries and is the reform of the demand side. In this paper, based on the daily data of the CNI Construction Materials index from January 2015 to July 2021, the ICSS algorithm and Garch $(1,1)$ method are used to analyze the characteristics of sub-samples divided by structural breakpoints. Moreover, it is concluded that the policy of green supervision can reduce the volatility of the stock of the Construction Materials industry and lead the index of the Construction Materials industry to develop steadily. Second, the Monthly data of the coal index and real estate index are introduced into the ADL regression model. The conclusion is that because of green policies such as green tax preferential, green technical support. Instead of decreasing the purchase intention, the Construction Materials index keeps increasing with the increase of the coal index. It illuminates that the reliance on coal is declining with the development of green transformation. So people tend to have more confidence in the future of Construction Materials.

Meanwhile, appropriate expansion of domestic demand and increase of the demand for real estate through the reconstruction of old cities and other policies can promote the development of the index of Construction Materials, but at the same time will increase its volatility. Therefore, It cannot reduce the risk of Construction Materials industry stock simply by stimulating the demand. We should start from green transformation to reduce the risk of Construction Materials industry stock to develop the Construction Materials industry.

\subsection{Suggestions}

Based on the empirical analysis of this paper, it can be concluded that the green industrial development policy can affect the volatility of Construction Materials stocks in the long term, so it is necessary to increase the intensity of green supervision and implement the coal tiered charging system to promote pollution reduction 
and carbon reduction. At the same time, the government should vigorously promote green Construction Materials by developing clean energy, eliminating high energy consumption and high pollution enterprises, improving green manufacturing capacity. Moreover, improve resource utilization rate by introducing new technology and developing circulating production.

Secondly, pushing forward the development of the Construction Materials industry through the demand-side reform of infrastructure Construction and real estate industry can promote the development of the Construction Materials industry. However, it can not reduce the volatility of its stock price. Only through the supply-side reform can fundamentally promote the innovative and high-quality development of the Construction Materials industry. Supply-side reform needs to use advanced technological advantages such as 5G artificial intelligence and big data to promote the digital development of Construction Materials. Aiming at high-quality development, we will improve the management system, elevate industry standards, unify regional standards, give preferential policies to green enterprises, optimize the synergy degree of industrial clusters, and promote coordinated development. Develop green industry-leading enterprises, leading small and medium-sized enterprises. We will promote integrated development among industries and promote the integrated development of green Construction Materials and green Constructions.

\section{REFERENCES}

[1] Zhuo J , Kumamoto M . Stock market reactions to COVID-19 and containment policies: A panel VAR approach[J]. Economics Bulletin, 2020, 40,32963305 .

[2] Fang Zhenming, Wang Chunfeng. Analysis of China's stock market fluctuation structure by ICSS method [J]. Journal of Harbin Institute of technology, 2009(10):302- 305.

[3] Ali Babikir; Rangan Gupta; Chance Mwabutwa; Emmanuel. OwusuSekyere;Structural breaks and GARCH models of stock return volatility: The case of South Africa. Economic Modelling 29 (2012) 2435-2443

[4] Wen Bin, Liu Chun, Jin Hongfei.The impact of macroeconomic factors on the stock return rate of China's industry [J]. Finance and Trade Economics,2011(06):51-59.

[5] Li Guozhang, Huo Zongjie.Energy consumption, energy consumption structure and economic growth in China: An empirical study based on ARDL model [J]. Contemporary economic science, 2010, 32(03):55-60+125-126.

[6] Guo Wenjia, Chen Yangjun, Xie Hongtao.Research on price Fluctuation Mechanism and Key Influencing Factors of Building Materials [J]. Chinese Market,2015(52):182- 183+185. 